cases at from six to nine minutes. Curve 4 has polnts of correspondence with the other three curves, but the variations occur in more elongated form. These constitute one type of $\in$ ffect.

With tincture 10, on the otber hand, excepting for an immediate and ahort-lasting drop in one case, the flow rises with the onset of digitalis, and is maintained at a rate above the normal during the first half of the experlment, untll the tonus of the heart has begun to rise in a marked degree, when the flow falls below the normal (Fig. 4). This marked increase of flow cannot be due to a rise of pressure, seelng that the pressure of the fluld entering the coronary vessels is in these experiments kept constant throughont their course. Nor can the greater flow be attributed wholly to increase in rate and strength of beat; variations of heart-beat may influence to a certain extent, but will not wholly account for the varia. tions of flow which have been recorded. This can be shown from many experiments; to give one Instance-the normal rate of beat was 200 per minute, the rate of flow 25 c.cm.; two minutes aiter the onset of digitalls the rate of beat was 196, the force being also diminished, but the flow was $31 \frac{1}{2}$ c.cm. per minute; six minntes later the rate of beat was 108 and the flow 40 c.cm. per minute. The only conclusion to be drawn is that a direct action on the coronary vesgels had taken place.

In dwelling upon the differences observed between the action of tincture of digitalis from sample to sample, examples have been chosen from among the best.marked cases. With some tinctures these differences do not come out clearly ; the samples cannot be said to belong to elther "tope."

To what the differences of action are due, and whether they are of importance from the point of view of practical testing - whether, for instance, an observed tendency in a tincture to produce delirium cordis should be held to detract from the value of that tincture-are questions at present difficult to answer. Further investigations might throw light on the causes of the variations observed. To hazard a conjecture, It seems possible that the constituent glucosides of digitalis may affect differently or in different degrees the various propertles of the heart, and a preponderance of one glucoside over another in a tincture may give different results on that account. It would be useful to test reliable preparations of digitoxin and its fellows in the same way that these tinctures have been tested, with a view to tracing to its source each variety of effect.

The slowing of the heart-beat, which is so characteristic a feature of digitalis action, occurred with most of the samples tested. Fig. 1 is a good example. In some of the experiments, however, a correction has to be made for changes of temperature, and at present the amount of the necessary correction cannot be estimated.

The strength at which the drug was used (for reasons alxeady mentioned) is less favourable, to the demonstration of slowing effects than are weak solutions, such, for example, as those employed by Dixon ' and Haynes." In testing the Jater samples, an experiment with the tincture at 1 in 1,000 was made, In addition to two or three experiments with the 1 in 200 solution, in order to bring out more clearly these effects.

In conclusion, it may be said that by the method here adopted it is possible to ascertaln with regard to 8 tincture (1) its "strength"; (2) its capacity: for producing "therapeutle results "-for example; slowing of the heart's beat and increase of its amplitude; (3) Its tendency to cause disorganization of the heart's rhythm. It may be stated here that great care was taken to keep the conditions of experiment as constant as possible, much trouble belng expended in securing animals of approximately similar age and weight. The number of experiments made amounted in all to 98 .

It has not at present been shown whether very small differences in alcoholic strength, snch as may exist between one fresh tincture and another (the samples used were all fresh) could modify their action on the heart when the tinctures are used at a strength of 1. In 200.' Such differences in the samples so far examined should be very small. It would be desirable, however, to make some experiments with a vlew to possible fallacies in thls direction, especially since it has recently been shown by Diron" that very small amounts of alcohol in
Ringer's solution affect the calibre of mammalian blood vessels.

The inquiry was undertaken In the first instance at the suggestion of Messrs. Evans, Sons, Lescher, and Webb. $I$ bave to thank them for supplying a great part of the material and a number of the various samples tested. 1 Dixon, Transactions of the Britigh Pharmaceutical Conference,
Brigbton, 1905. 2 Dixon, Manual, of Pharmacology, p. 173. $\mathbf{3}$ Haynes, Bio-chemical Journal, February, 1906. \& Dixon, Journal of Physiology,
March 27th, 1907, p. 357.

\section{ON MIGRAINE.*}

By T. H. B. DOBSON, M.D.LOND. WINDERMERE.

You may remember the advice glven by Gobind the One-eyed to the author of Life's Handicap, when asked by the latter (as to the art of telling tales) "in what manner is it best to set about the task, $O$ chiefest of those that atring pearls with their tongue?" and Gobind replies, "Do thon this: tell them first of those things that thou hast seen and they together. Thus will their knowledge piece out thy imperfections."

And thus it is that I have chosen migralne as the subject of this short paper, seeing that we have all met with numerous cases, and also as I have had an intimate if unwllling, acquaintance with this interesting disorder. I hope that you, with your knowledge, will piece out my imperfections.

The word, of course, is the shortened form of hemicrania, and represents a definite entity, and must not be used, as it so often is, for headaches from whatever canse.

We call migraine a Iunctlonal disease (thereby meaning that as yet we have discovered no organic basls), which $1 \mathrm{~s}$ characterized by paroxysmal attacks of headache, usually one-sided, and which may be associated with sickness, peculiar affections of sight, and various mental symptoms.

If each disease conld have its description written by one who has himsell suffered, we should have truer and more graphic accounts to read, and our textbooks would be far more interesting.

\section{EtroLoGY.}

We must look upon migraine as heredlary to a large extent. Perhops one should say that the tendency to suffer from a neurosis is hereditary, but that the neurosis may appear in one generation as migraine, in another as spasmodic asthma, etc.

A patlent who auffers from migraine generally has one parent gouty or a sufferer from migraine. The age of onset is variable, most cases begin about puberty, and on the other hand most cases improve about the age of 60 .

Women are gaid to suffer more than men; but in my experience there has been a preponderance of men. Goodhart speaks well of us, he says, "migrainous subjects mostly come from the ranks of the temperate livers, who often work their brains to exhaustion."

As to the primary cause of the disease, at present we can only say that there is an hereditary predisposition to a brain storm. When we come to the immedlate and exciting causes, one generally finds that mental or bodily fatigue, worry, or eyestrain are responslble. Typlcal canses are a cinematograph exhibition, a tour round a picture gallery, and prolonged microscopical work. I have never noticed in my own case, or in those of my iriends, that errors in diet have produced a migrainous attack. It is often stated to the contrary in the textbooks, but 80 much the worse for the textbooks. A fatiguing journey, followed by a full meal taken on a hungry stomach, may predispose to an attack, but I am inclined to blame the fatigue and not the food.

SxмPToms.

May I begin by describing an attack of which I was the victim a few weeks ago? In the morning, while visiting a patient. I noticed that the lady's nose had become lnminons and was trembling, and $I$ knew that $I$ was in for an attack. The area of disturbance was just below the central point of vision. Of course both eyes are equally * A paper read before the North Lancashire and south Westmorland *A paper 
affected and the lights keep dancing even though one shuts one's eyes. In five minutes the area had increased, so that if I looked a little to one side of the lady's face the whole of her head was blotted out of my vlsion. The advancing edge of the area was especially brilliant, the central part being blind. During the next fifteen minutes the disturbance increased in extent, but never involved the central point of vision. With me the central point of vision is never affected, but this is not the rule. It often begins just to one side of the central polnt and then extends outwards and around.

One's area of vision by this time is greatly reduced, for most of the field of vision is filled with a boiling sea of light. The lights at the advancing edge assume a zlgzag form similar to that moulding called "Dog-tooth" seen in early English Gothic architecture. The luminous area is impenetrable and shats out all vision from that quarter. One sees people with trunks but no legs, and legs without trunks. Of course, this is only relatively true, for the moment that one moves one's eyes one sees the rest of the object, whilst the part first seen disappears in a bolling sea of light. The term "fortification figures" is uged for the appearance, since the form assumed corresponds to the ground plan of a fort, all angles and corners.

During the fifteen minutes or 80 that the fortification figures have been developing there comes on a certain amount of mental numbness. One cannot think very acutely, and one has to content oneself (during a bad attack) with talking platitudes. One loses one's powers of concentration, and I have noticed myself answering questions in a mechanical sort of way. A feeling of nause fixes one about this time ; and now, about twenty to thirty minutes after the first symptoms have appeared, the blindness on one side is complete, and one walks into people or chairs without being consclous of their existence

Subsidence of the symptoms is rapid, and in another five minutes the blind area has shrunk or dlsappeared, and a headache gradually makes its presence felt on the side of the head opposite to that on which the blindness appeared. The headache lasts twenty-four to thirty-six hours. With me vomiting has never occurred.

This may be taken as a brlef account of the chlet eymptoms of migraine; but I would point out that all cases do not present these eymptoms. I would follow Livelng's classification:

1. Simple Hemicrania, typical in that it is unilateral and responds to every arterial beat; it recurs every few weeks.

2. Sick Headache, again periodical; unilateral headache calminating in nausea, followed by vomiting and prostration; hereditary.

3. Blind Headache, such as I have already described.

But there may be other and more alarming symptoms grafted on to any case of mlgraine:

(a) Tingling of lips or the arm.

(b) Numbness of arm.

(c) Drowilnes3.

(d) Aphasia (motor aphasia)

(e) Squint (temporary paralysis of third nerve).

There is a form of the disease which I have not seen described in the textbooks, but which is occasionally met with-namely, one that might be termed the "status migralnicus" (from analogy to status epllepticus), in which one attack is Immediately succeeded by another, oo that the patlent is for several hours troubled by the lartification îgures and the blindness.

Another point worth mentioning is, that when a patient complains of waking in the morning with a typlcal hemtcranla, and you ask. "Were you dreaming last night?" they will tell you "Yes"; and on asking the nature of the dreams they will often say that vivid lights played an important part in them. This seems to show that the fortification figures may be appreciated during sleep without actually waking the sufferer.

$\Delta$ Irlend of mine, who has anffered for thirty years from migraine, volunteered the statement that for many years before the typlcal attacks came on he used to dream of lights, and in the mornings to wake with headache.

\section{Diagrosis.}

The headache is quite typlcal in that it responds to every heart beat, is made intolerable by stooping and coughing, and is in the great majority of cases unilateral. The character of the headache, its periodiclty, and usual association either with vomiting or blindness, makes the diagnosis easy.

Gowers has pointed out the numerous cases in which migraine has been mistaken for epilepsy. I shall allude to this directly.

A diagnosis of cerebral tumour might be made if the classical symptoms of both diseases were not inquired into.

\section{Pathologr.}

Attempts have been made to show that the headache of mlgraine is the referred pain set up by disorders of the viscera. This cannot be so, for the areas of the cutaneous nerve supply associated with the visceral nerve supply should also be affected, and they are not; also the character of the pain is different. I need hardly mention that the fortification figures cannot be due to disturbance of the retina primarily, for both eyes are affected, and the homonymous hemianopla shows that the disturbance must be sltuated behind the optlc chlasma, possibly in the optic thalamus.

During the attack there seems to be a contraction of the vessels of the part affected, causing depressed activityfor example, anaesthesia of the skin, loss of power of co-ordination, delayed digestion, mental lethargy, and partial blindness. When the attack is passing off, we have the arterles previously contracted now becoming dilated, and one experiences the headache, which responds to every heart beat, and which may be temporarily lessened by pressure on the carotid.

As to the actual nature of the attack, we can only say that it is one of a large group of nerve storms which are liable to sweep over the human organlsm-epllepsy, spasmodic asthma, tlc douloureux and others. Certain constitutions seem to accumulate stores of nervous energy, whlch are liberated in one of these explosive methods. It may be we are laying up a store of poison which aecumulates until the nervous system can stand it no longer. Haig, himself a sufferer from migraine, naturally puts it down to uric acid, and says that he can free himself from attacks by dieting.

Most observers seem to think that a poison is absorbed from the much-abused intestinal tract, and that eyestrain, fatigue, and hunger are only the matches which light the fuse.

\section{Treatment}

I.-To Lessen the Tendency to the Explosive Action in the Nervous Centres.

Trousseau says: "In proportion as the nutritive and vegetative functions are feeble and languishing, nervous phenomena are mobile, exalted, irregular." To alter this condition belongs to the rudiments of medicine, and need not detain us. I need only point out the necessity for sufficiency of sleep, nutritious food (but not excossive in quantity) prevention of intestinal fermentation, and regular exercize. Haller cured himself by taking large quantities of water every day and a light dietary. Linnaeus also. (I am now quoting from Liveing.) " Marmontel," says Labarraque, "who was for seven years tormented by paroxyems of a very painful character, and who consulted the Queen's physician to no purpose, cured, himself by following the prescription of a farrier, who advised him to drink water, eat little, and take exercise."

II.-To Avoid the Immediate Exciting Causes.

These are : (1) Gastric disturbance; (2) constipation; (3) eyestraln (by wearing +1 collndrical lenses for reading, I was able to reduce my attacks very considerably).

Gowers speaks highly of nitroglycerine. I have not tried it regularly. I have tried amyl nitrite inhalations when the attack was developing, hoping to overcome the arterial contraction, but, in addition to the headache of migraine, I had to put up with that caused by amyl nitrite.

The suggestive lectures by Gowers on the borderland of epilepsy opens up an interesting field for discussion. I think the chlef points are these :

1. In rare cases migralne alternates with epilepsy.

2. Migraine may develop into epllepsy.

3. The tingling gensation, which may come on in the finger and gradually pass up the hand and arm during the twenty minutes in which the fortlfication figures are developing in migraine, may also occur as an aura of epllepsy ; but in this case it is only momentary. 
4. Headache follows both; that of migralne being more severe.

5. The aura of migraine seldom affects a leg or. the trank.

6. Somnolence may occur in both.

As Gowers agys, "It is curlous that the most frequent relation between epilepsy and migraine is as a source of error between the two." Of course, one always has to remember that they are both comparatively common complaints, and there will be a natural overlapplng, apart from any affinity.

The antecedents of migraine are migraine or gout, those of epllepsy belng epllepsy or insaulty. In migraine there Is no deterioration of mind.

\section{THE REMOVAL OF FOREIGN BODIES FROM} THE AIR AND FOOD PASSAGES.

Bx D. R. PATERSON, M.D., M.R.C.P.,

SÜRGRON TO THE EAR AND THROAT DEPARTMENT, CARDIFF IN.IRMARY ; HONORARY SURGEON FOR DISEASES OF EAR AND THROAT,

$$
\text { ROYAL SEAMEN'S HOSPITAL, CARDIFF. }
$$

Amosg the cases of foreign bodies in the air and food passages which came under my department during the last twelve months, two are of special interest, and appear to be worthy of record. While illustrating the ease with which such forelgn bodies can be extracted even from deep-lying sites by means of the direct method, they show, at the same time, the importance in using it of having good illuminating power. They will also serve, I hope, again to call attention to this admirable mode of treatment; as it has hardly received in this country the attention it deserves.

\section{Nutshell in the Left Bronchus-Extraction by} Bronchoscopy.

A young sallor, 18 years old, was admitted to hospital in January suffering from difficuliy of breathing. He was eating nuts whilst playing "leap-frog," and aspirated part of a nutshell into his larynx. He had a severe suffocative attack lasting some time, during which he was partially opanosed and in great distress. After a while the obstruction appeared to become displaced, and, whlle the breathing was reileved, discomfort was felt lower down in the chest. When seen, twelve hours later, he complained of a feeling of constriotion of the chest and cough, and wheezing was audible. Beyond rhonchi heard over the larger air tubes there were no definite rhonchi heard over the larger air tubes there were no definite
physical signs to be made out in auscultation. He was put ander chloroform, which he took rather badly, there being much cough and cyanosis. After the upper part of the respiratory traot had been well cocainized, a Killian tabe $9 . \mathrm{mm}$. In diameter was passed through the largnx into th trachea, which was Injected and intensely red and contained much frothy mucus. This was raplaly removed by means of the saliva pump and cocaine applied to the lower means sages. The tabe was passed down the right bronchus, whtoh was explored as far as the second ramification and found Was explored as far as the second ramification and found
empty. Its mucous membrane was much injected, probsbly explained by the fact that the patient had been suffering from " "bronchial cold" for some days. In searching the left bronchus a mass, reddish in colour, was fonnd blocking it jast bslow the commencement, but lts relations were difficalt to make out owing to the insufficient lllumination given by a worn-out lamp. The examination was accordingly suspended, and on the following dey the patient was agsin plased under the influence of chloroform, which he this time took very well. Using a new lamp giving a greatly-improved light, I passed the tube at once down to the left bronchus, I passed the tube at once down to the left bronchus, was made out to be the plece of nutshell lying inslde the bronchus having a small hook-like process over the bifurcetion. The convexity of the shell was uppermost, and from ander it a constant stream of frothy mucus poured out of the bronchus. Its.red colour closely resembled that of the adjacent mucous membrane, and it was the greyish tint of the part of the'shell next the blfarcation which enshled its exset part of to be recognized. A Killian long forceps was passed down the hooked end was seized and the noreps was passed down, the hooked end was seized and the nutshell drawn out along with
the tube. The whole procedure did not last more than a the tube. The whole procedure did not last more than
quarter of an hour. The patient left hospital two days later.

The object removed was a Iragment of a Spanish nutshell measuring $2 \mathrm{~cm}$. by $1.6 \mathrm{~cm}$. (Fig. 1). Its outer smooth conver surlace was of a unlform red colour resembling that of the bronchial mucous membrane. Towards the apex, where it terminated in a hooklike process, it had more of a greyish tint, and this was the only point which stood out in contrast to Its surroundings. Foreign bodies in the bronchl usually become covered with mucus and ass ume a grey appearance which renders their identification from the adjacent structures easy; but in this case the polished surface of the shell afforded no hold to a mucous covering, and the entrance of the bronchus looked at first sight as it it were

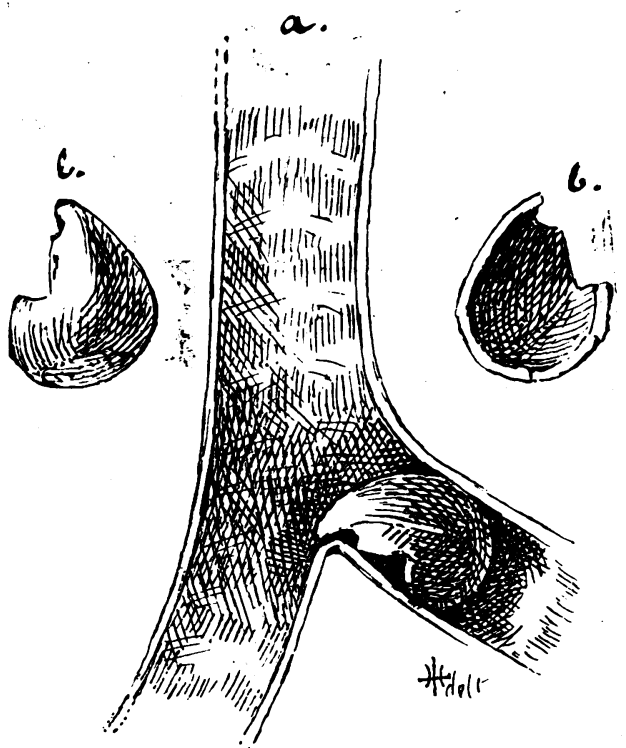

Fig. 1.-Nutghell (a) impacted in left bronchus; (b) after removal.

filled by a smooth globular swelling. The use of a good light soon revealed, however, the condition of things; and, the exact relations having been ascertained by means of a probe, the extraction presented no special difficult?.

Plum Sione in the Oesophagus: Removal by Oesophagoscopy.

A Norwegian sailor, aged 16, was admitted in June, 1907, with diffionlt in swallowing 80 complete that nothing had been passed for forty-elght hours. There was a complete block of passed for forty-etght hours. There was a complete block of the gallet, and this had come on atter swallowing a plum stone. Attempts to dislodge it had been made cess. On admission the resident medical officer passed soft bougies, and found that a small size could be got as far as the cardisc end of the oesophagus, where it stopped, and a large slze was arrested about the middle of the chest. He wisely refrained from employing any force or using a coln-catcher. The patient was placed under chloroform, and an oesophagoscopio tube of $13 \mathrm{~mm}$. dismeter passed down an oesophagescopic tube of $13 \mathrm{~mm}$. dismeter passed down until it was stopped about 8 in. from the teeth by a narrowing of the gullet, which was emphasized by spasm. But even abolition of the spssm under deep ansesthesia did not permit its passage. Accordingly a tube of $9 \mathrm{~mm}$. diameter was introduced, and this went through the narrow part without diffculty. It was carried as far as a short distance above the cardlac orifice 12 in. from the teeth, where the plum stone was found lying transversely across the gullet. The mucus was wiped away, and the exact relations of the body ascertained by the probe. It was readily grasped by the forceps, and was being drawn up along with the tube, into which, and was being drawn up along with the tube, into which, on account of its size, it could not enter, when it stuck at the narrow part and the forceps slipped. This bappened
twice. By a little manipulation the plum stone was turned twice. By a little manipulation the plum stone was turned lengthwise and then grasped, after which it was mar cavred through the constriction and brought out along with the tabe. We subsequently learned that the patient when a child had careful in eating. A few years ago ho had trouble with food which remained in the oesophagus for several days.

The size of the fruit stone extracted (FIg. 2) was $2 \mathrm{~cm}$.

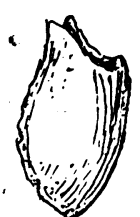
by $1.2 \mathrm{~cm}$. It had a sharp hook-llke
process at one end. This was embedded In the mucous membrane of the cardis and a forcible attempt to push down the stone would certainly have led to laceration. As a rule a forelgn body is easily recognized, standing out, as it generally does, in sharp contrast to the Fig. 2. - Plum pink tint of the mucous membrane. In stone extracted this instance, again, the red colour of the from cardiac end forelgn body gave no such distinction, of oesophagus. - Iorelgn body gave no such distinction, brilliant illumination was indlspensable.

The general technique of the method of removing forelgn bodies by bronchoscopy and oesophagoscopy I have already 